\title{
Characterization of an Atmospheric Air Non-thermal Plasma Device in Relation to Ozone Production
}

\author{
Mooktzeng Lim, Kanesh Kumar Jayapalan, Ahmad Zulazlan Shah Zulkifli, Hamdan Hassan, Kailok Lai, \\ and Oihoong Chin
}

\begin{abstract}
An atmospheric air non-thermal plasma (NTP) device is characterized in relation to ozone production. The electron density, $n_{\mathrm{e}}$, electron temperature, $T_{\mathrm{e}}$ and ozone concentration are measured for three dielectric barrier discharge (DBD) geometries, i.e., ten tubes of $10 \mathrm{~mm}$ outer diameter (OD), six tubes of $25 \mathrm{~mm}$ OD, and three tubes of $40 \mathrm{~mm}$ $O D . n_{\mathrm{e}}$ and $T_{\mathrm{e}}$ are deduced using optical emission spectroscopy via the line ratio method and the ozone concentrations are measured by using an ozone meter. $n_{\mathrm{e}}$ and ozone concentrations were the highest for the three tube $-40 \mathrm{~mm}$ configuration, showing a correlation between the number of charged particles and ozone production.
\end{abstract}

Index Terms-Dielectric barrier discharge, environmental treatment, non-thermal plasma, ozone.

\section{INTRODUCTION}

Non-thermal plasma (NTP) can be produced from dielectric barrier discharge (DBD) reactors, and can consist of either a single insulated electrode, two insulated electrodes or an insertion of a dielectric barrier in the space between both electrodes [1]. In atmospheric air, DBDs are able, via ionization, to produce chemically active species such as oxygen and hydroxyl radicals. These reactive species are useful in various applications, such as surface modification [2], [3], flue gas [4] and waste water treatment [5], assisting in combustion [6], [7] and for fuel synthesis [1]. The production of these reactive species is affected by the properties of the plasma, such as the electron density, $n_{\mathrm{e}}$ which is the number of electrons per unit volume produced by the discharge, and the electron temperature, $T_{\mathrm{e}}$ which gives the average energy of the electrons produced by the discharge. Hence, it is important to measure these two parameters. One of the important reactive species is ozone which is commonly produced in electrical discharges in air, and this work attempts to correlate the ozone production to $n_{\mathrm{e}}$ and $T_{\mathrm{e}}$.

It is not suitable to use the conventional electrostatic Langmuir probe to measure the $n_{\mathrm{e}}$ and $T_{\mathrm{e}}$ for atmospheric pressure discharges. A non-invasive method is preferable, and the proposed method here is to use the optical emission spectra via the line ratio method; whereby, the measured intensity ratio of two electronic transitions of a discharge gas

\footnotetext{
Manuscript received March 22, 2016; revised July 15, 2016. This work was supported TNB's funding (TNBR/SF 195/2015).

Kanesh Kumar Jayapalan, Kailok Lai, and Oihoong Chin are with the Plasma Technology Research Center, Physics Department, University of Malaya, Malaysia (e-mail: ohchin@um.edu.my).

Ahmad Zulazlan, Hamdan Hassan, and Mooktzeng Lim are with the Fuels and Combustion section, Generation Unit, TNB Research (TNBR) Sdn. Bhd., Kajang, Malaysia (e-mail: mooktzeng.lim@tnbr.com.my).
}

element is used for the fitting and deduction of the aforementioned parameters. For a discharge in atmospheric air, the most commonly observed electronic transitional bands are from molecular nitrogen. Hence, the line ratio method can be applied by taking the intensity ratios of two vibro-rotational emission peaks from different nitrogen transitional band systems (e.g., second positive system and first positive system [8] or second positive system and first negative system [8]). These ratios are fitted to deduce the electron energy distribution function (EEDF) and electron drift velocity, $v_{\mathrm{d}}$ of the discharge electrons, which can be subsequently used to calculate $n_{\mathrm{e}}$ and $T_{\mathrm{e}}$.

This study will characterize and compare differences in $n_{\mathrm{e}}$ and $T_{\mathrm{e}}$ for a NTP rig with different DBD geometries. As the rig would be used for environmental and combustion purposes, the ozone emissions are measured for the different geometries and are correlated to $n_{\mathrm{e}}$ and $T_{\mathrm{e}}$.

\section{METHODOLOGY}

\section{A. Experimental Set-up}

Fig. 1(a) shows the schematic of the NTP rig in TNBR. The rig has an enveloping cylinder of inner diameter $110 \mathrm{~mm}$ that acts as the ground electrode. Silica tubes with a thickness of 2 $\mathrm{mm}$ are used as the dielectric barrier, and are held in place by a Teflon holder. The tubes are arranged in different geometries, consisting of i) ten tubes of $10 \mathrm{~mm}$ outer diameter OD each, ii) six tubes of $25 \mathrm{~mm}$ OD each, and iii) three tubes of $40 \mathrm{~mm}$ OD each, respectively. The inner surface of the silica tubes are lined with copper sheets that are connected to the high voltage supply. The shortest gap between silica tubes and the outer enveloping shell is $1 \mathrm{~mm}$.

The input power into the NTP rig is supplied by a high voltage (HV) power supply (PVM 2000). The HV source includes a $2 \mathrm{~kW}$ VARIAC that controls the total power to the load, while the current is controlled by the duty cycle which provides the current pulses. The frequency is adjustable while a digital meter allows the operating frequency to be displayed. An individual analogue voltage meter reads the DC voltage of the power amplifier, and an oil filled transformer is also provided.

The discharge power from the NTP rig can be determined by connecting a capacitor in series $(0.22 \mu \mathrm{F})$ to the electrode before grounding. The use of capacitor to determine the power dissipated in the DBD is a common practice in literature, since the voltage crossing the series capacitor $\left(V_{\mathrm{c}}\right)$ is proportional to the charge crossing the electrodes [9]. The capacitor is connected to an oscilloscope to determine the 
voltage across the capacitor, $V_{\mathrm{c}}$. From $V_{\mathrm{c}}$, the charge accumulated in the capacitor can be determined via $Q=C V_{\mathrm{c}}$. A Lissajous diagram (e.g., a plot of the charge $Q$ versus voltage input $V_{\text {in }}$ ) can then be obtained. The discharge energy per cycle is determined by calculating the area under the curve. From the Lissajous diagram, the discharge power for different voltages, duty cycle, and electrode configurations was determined.

A Fluke 1750 clamp meter was used to measure the current and voltage drawn from the main supply (i.e., $I_{\text {main }}$ and $V_{\text {main }}$, respectively) into the set-up for different voltage inputs, duty cycle, and electrode configurations. The different values of current input and voltage input will be used to develop the dimensionless correlation for estimating the discharge power.

The spectrometer is an AvaSpec-ULS2048 Starline model from Avantes that has four channels that are able to measure optical emissions in the ultraviolet (UV), visible (VIS) and near infrared (NIR) regions. Each channel covers wavelengths of 200 to 458,455 to 683,680 to 974 and 870 to $1030 \mathrm{~nm}$ respectively. The first two channels have UC, VC gratings while the final two channels have NC gratings. All channels are equipped with 2048 pixel CCD detectors, with a grating resolution of 1200 lines/mm and a slit width of $10 \mu \mathrm{m}$. All four channels of the spectrometer are connected to a $2 \mathrm{~m}$ four-furcated cable. The cable has a fibre optic probe at the end that is used to detect the optical emissions from the NTP rig. The AvaSoft spectrometer software is able to display and record the optical emissions in terms of spectral lines. From the experimental spectral lines, a mathematical model is used to estimate $n_{\mathrm{e}}$ and $T_{\mathrm{e}}$.

An ozone meter (UV-106L Ozone Analyzer, Ozone Solutions) was used to measure the ambient concentration of ozone as a result of the ionization process from the NTP. The measurements were averaged over a period of $10 \mathrm{~min}$.

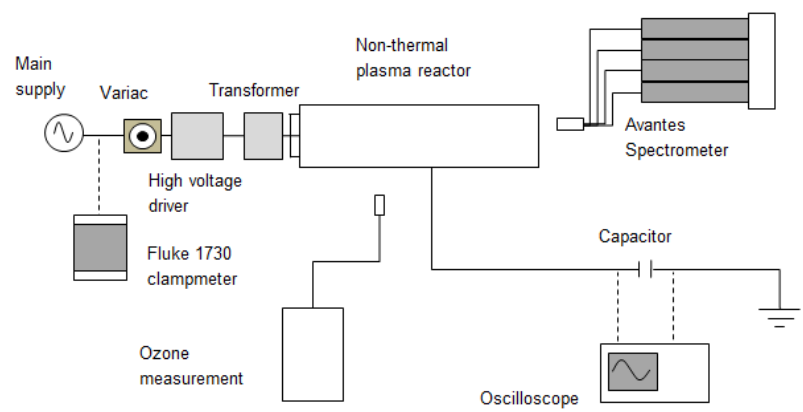

Fig.1. Schematic of non-thermal plasma test rig.

\section{B. Modeling of Electron Density, $n_{e}$ and Electron Temperature, $T_{e}$}

A model has been developed to calculate the electron number density, $n_{\mathrm{e}}$ and electron temperature, $T_{\mathrm{e}}$ of the atmospheric NTP using the MATLAB software. The required input parameters of the model are the average current density, $J_{\text {ave }}$ of the discharge and the spectral line intensity ratio.

For air plasmas at atmospheric pressure (with $78 \%$ Nitrogen, $\mathrm{N}_{2}$ and $21 \%$ Oxygen, $\mathrm{O}_{2}$ composition), the observed spectral lines (Fig. 2) are primarily from the $\mathrm{N}_{2}$ molecular and $\mathrm{N}_{2}^{+}$ionic band transitions, known respectively as the second positive system $\left(\mathrm{N}_{2} \mathrm{C}^{3} \Pi_{\mathrm{u}} \rightarrow \mathrm{B}^{3} \Pi_{\mathrm{g}}\right.$ or $\left.\mathrm{N}_{2}(\mathrm{C}-\mathrm{B})\right)$ and the first negative system $\left(\mathrm{N}_{2}^{+} \mathrm{B}^{2} \sum_{\mathrm{u}}^{+} \rightarrow \mathrm{X}^{2} \sum_{\mathrm{g}}^{+}\right.$or $\left.\mathrm{N}_{2}^{+}(\mathrm{B}-\mathrm{X})\right)$.

Taking the measured ratio of the most intense peak $\left(v^{\prime}-v^{\prime \prime}=(0-0)\right)$ of the second positive system at $337.1 \mathrm{~nm}$ and the first negative system at $391.4 \mathrm{~nm}$ (with consideration of the spectral efficiencies at each wavelength) it is possible to infer the electron velocity distribution by means of fitting with the following equation [10]-[13],

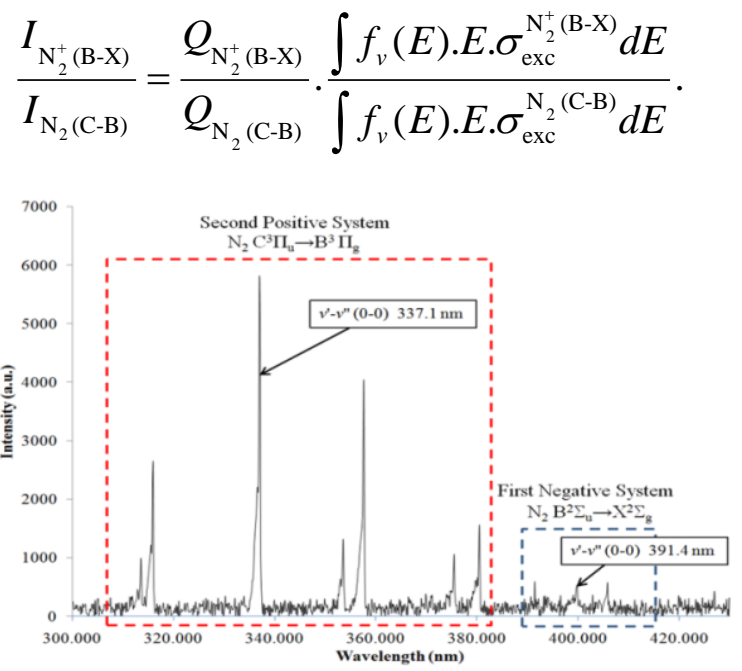

Fig. 2. Measured spectral lines from $300-450 \mathrm{~nm}$ for the discharge at $1.5 \mathrm{~A}$ for the 10 tube configuration.

Here, $E$ is the energy of the electrons in eV, $f_{v}(E)$ is the electron velocity distribution function (EVDF) in $\mathrm{eV}^{-3 / 2}$ and $\sigma_{\text {exc }}^{\mathrm{N}_{2}(\mathrm{C}-\mathrm{B})}$ and $\sigma_{\text {exc }}^{\mathrm{N}_{2}^{+}(\mathrm{B}-\mathrm{x})}$ are the electron impact excitation cross sections for the second positive and first negative system transitions in $\mathrm{m}^{-2}$ [14], respectively.

$Q_{\mathrm{N}_{2}(\mathrm{C}-\mathrm{B})}$ and $Q_{\mathrm{N}_{2}^{+}(\mathrm{B}-\mathrm{X})}$ are the rate coefficient ratios of the de-excitation and emission processes involved in the second positive and first negative systems respectively, and are given by:

$$
Q_{\mathrm{N}_{2}(\mathrm{C}-\mathrm{B})}=\frac{A^{\mathrm{N}_{2}(\mathrm{C}-\mathrm{B})}}{A^{\mathrm{N}_{2}(\mathrm{C}-\mathrm{B})}+k_{q}^{\mathrm{N}_{2}(\mathrm{C}-\mathrm{B})}\left[\mathrm{N}_{2}\right]+k_{q}^{\mathrm{N}_{2}(\mathrm{C}-\mathrm{B})}\left[\mathrm{O}_{2}\right]} .
$$

and

$$
Q_{\mathrm{N}_{2}^{+}(\mathrm{B}-\mathrm{X})}=\frac{A^{\mathrm{N}_{2}^{+}(\mathrm{B}-\mathrm{X})}}{A^{\mathrm{N}_{2}^{+}(\mathrm{B}-\mathrm{X})}+k_{q}^{\mathrm{N}_{2}^{+}(\mathrm{B}-\mathrm{X})}\left[\mathrm{N}_{2}\right]+k_{q}^{\mathrm{N}_{2}^{+}(\mathrm{B}-\mathrm{X})}\left[\mathrm{O}_{2}\right]},
$$

$A^{\mathrm{N}_{2}(\mathrm{C}-\mathrm{B})}$ and $A^{\mathrm{N}_{2}^{+}(\mathrm{B}-\mathrm{X})}$ are the spontaneous emission (Einstein) coefficients for the second positive and first negative systems respectively in $\mathrm{s}^{-1}[15] ; k_{q}^{\mathrm{N}_{2}(\mathrm{C}-\mathrm{B})}$ and $k_{q}^{\mathrm{N}_{2}^{+}(\mathrm{B}-\mathrm{X})}$ are the molecular quenching rate coefficients for the second positive and first negative systems respectively in $\mathrm{m}^{3} \mathrm{~s}^{-1}[15] .\left[\mathrm{N}_{2}\right]$ and $\left[\mathrm{O}_{2}\right]$ are the atmospheric nitrogen and oxygen densities in $\mathrm{m}^{-3}$. $\left[\mathrm{N}_{2}\right]$ and $\left[\mathrm{O}_{2}\right]$ can be calculated by using the ideal gas law from percentage of composition, i.e.,

$$
\left[\mathrm{N}_{2}\right]=0.78 \frac{p}{k_{\mathrm{B}} T_{\mathrm{n}}} \approx 5.72 \times 10^{27} / T_{\mathrm{n}},
$$


and

$$
\left[\mathrm{O}_{2}\right]=0.21 \frac{p}{k_{\mathrm{B}} T_{\mathrm{n}}} \approx 1.54 \times 10^{27} / T_{\mathrm{n}},
$$

where, $p$ is the atmospheric pressure in $\mathrm{Pa}, k_{\mathrm{B}}$ is the Boltzmann constant in $\mathrm{J} \mathrm{K}^{-1}$ and $T_{\mathrm{n}}$ is neutral gas temperature of the measured plasma in K. For certain NTP conditions, $T_{\mathrm{n}}$ is typically assumed to be close to room temperature, i.e., $300 \mathrm{~K}$. In the present work, however, $T_{\mathrm{n}}$ was calculated via simulation algorithm [16] to account for the effects of neutral gas heating on discharge parameters.

The EVDF, $f_{v}$ is obtained by solving the Boltzmann equation for the electron collisional processes involved at the given conditions. A free Boltzmann solver program developed by Napartovich [17] was used for this purpose. The input parameters required for the program were the atmospheric gas composition, gas pressure and reduced electric field, $E / N$ (in Td). The reduced electric field is the ratio between the electric field of the discharge with the total number of particles in the vicinity. The EVDFs were calculated for an E/N range of 50-1000 Td at 50 Td intervals. Each of the obtained EVDF distributions was used to calculate equation (1). The calculated theoretical ratios of $I_{\mathrm{N}_{2}^{+}(\mathrm{B}-\mathrm{X})} / I_{\mathrm{N}_{2}(\mathrm{C}-\mathrm{B})}$ and fitted curve versus $E / N$ are shown in Fig. 3The fitted curve in Fig. 3 is used to match the ratios measured from experimental data and find the corresponding value of $E / N$, i.e., the reduced electric field of the discharge.

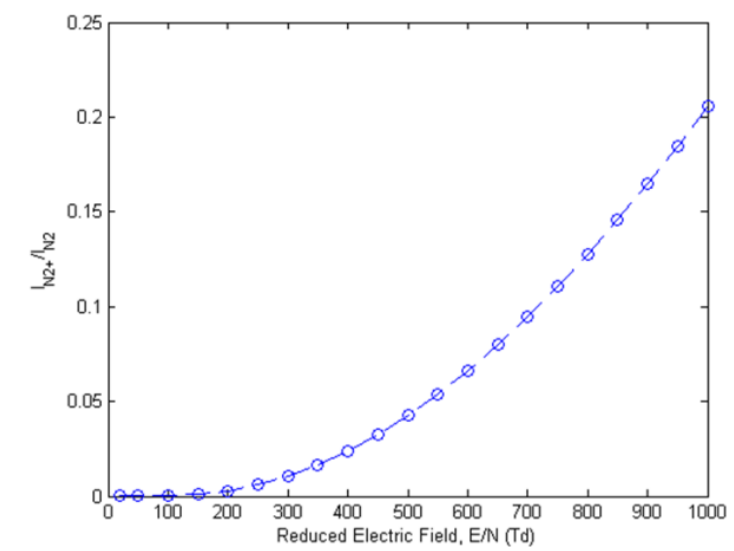

Fig. 3. Calculated theoretical ratios $I_{\mathrm{N}_{2}^{+}(\mathrm{B}-\mathrm{X})} / I_{\mathrm{N}_{2}(\mathrm{C}-\mathrm{B})}$ versus reduced electric field, $\mathrm{E} / \mathrm{N}(\mathrm{Td})$

Electron temperature, $T_{\mathrm{e}}(\mathrm{eV})$ can be calculated from the EVDF by using the following equation,

$$
T_{\mathrm{e}}=\frac{2}{3} \int f_{v}(E) \cdot E^{3 / 2} d E
$$

For convenience, $T_{\mathrm{e}}$ is first obtained versus $E / N$ at the same intervals as the theoretical ratios in Fig. 4; and is similarly fitted (Fig. 4). The fitted curve can next, be used to estimate $T_{\mathrm{e}}$ of the discharge by taking the earlier determined value of $E / N$ from the measured line ratio.

Besides calculation of the EVDF, the Boltzmann solver by Napartovich is also able to calculate the electron drift velocities, $v_{\mathrm{d}}$ for each input value of $E / N$. $v_{\mathrm{d}}$ can be briefly described as the velocity of the electron flow under the influence of an electric field. The electron density, $n_{\mathrm{e}}$ can be determined by $v_{\mathrm{d}}$ via,

$$
n_{\mathrm{e}}=\frac{J_{\mathrm{ave}}}{e \cdot v_{\mathrm{d}}} .
$$

Here, $e$ is the electron charge in $\mathrm{C}$ and $J_{\text {ave }}$ is the average current density of the discharge given by,

$$
J_{\text {ave }}=\frac{I_{\mathrm{D}}}{S_{\mathrm{D}}},
$$

where, $I_{\mathrm{D}}$ is the measured discharge current and $S_{\mathrm{D}}$ is the surface area of the discharge. As with $T_{\mathrm{e}}$ in Fig. 4, the reciprocal term, 1/e.v is plotted versus $E / N$ at the aforementioned intervals and fitted (Fig. 5). $n_{\mathrm{e}}$ of the discharge is then, estimated by multiplying $J_{\text {ave }}$ with the matched value of $1 / e . v_{\mathrm{d}}$ determined from the previously obtained $E / N$ of the discharge.

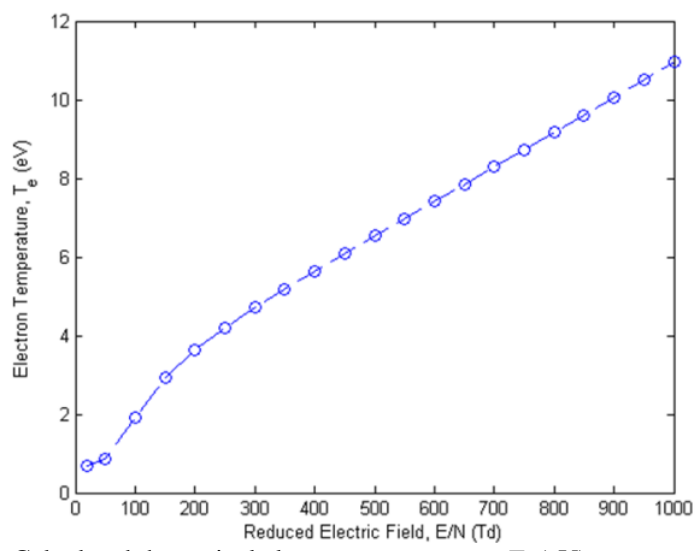

Fig. 4. Calculated theoretical electron temperature, $T_{\mathrm{e}}(\mathrm{eV})$ versus reduced electric field, $E / N$ (Td).

\section{RESULTS AND DISCUSSION}

\section{A. Electron Density, $n_{e}$ and Electron Temperature, $T_{e}$ for Different Geometries}

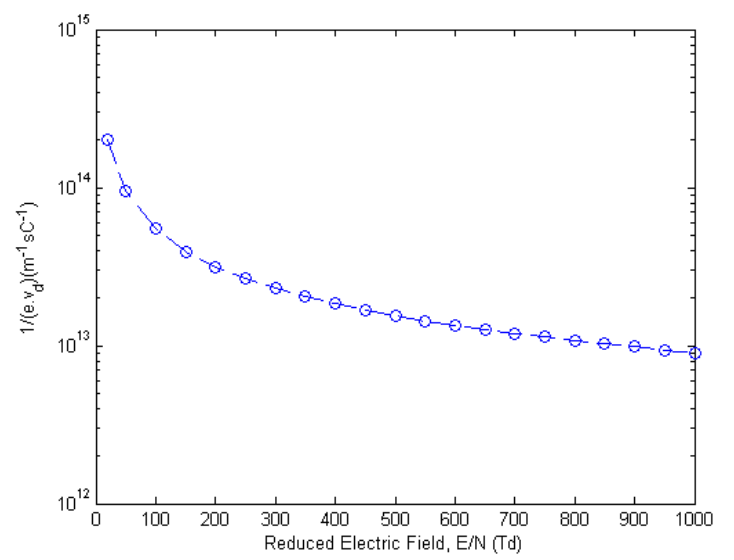

Fig. 5. Calculated reciprocal term $1 / e . v_{\mathrm{d}}$ (for calculation of $n_{\mathrm{e}}$ ) versus reduced electric field, $E / N(\mathrm{Td})$.

Fig. 6 shows the variation of $n_{e}$ with different electrode diameters and discharge power. The calculated range of $n_{\mathrm{e}}$ were $(0.67-0.75) \times 10^{14} \mathrm{~m}^{-3},(1.4-2.0) \times 10^{14} \mathrm{~m}^{-3}$ and $(1.9-$ 
2.7) $\times 10^{14} \mathrm{~m}^{-3}$ for the DBD geometries with the ten tubes of $10 \mathrm{~mm}$ diameter, six tubes of $25 \mathrm{~mm}$ diameter and three tubes of $40 \mathrm{~mm}$ diameter, respectively. $n_{e}$ increases with the lower number of tubes due to the stronger electric fields generated (i.e., the same input power is divided across less tubes), allowing for increased ionization and collisional excitation of plasma electrons.

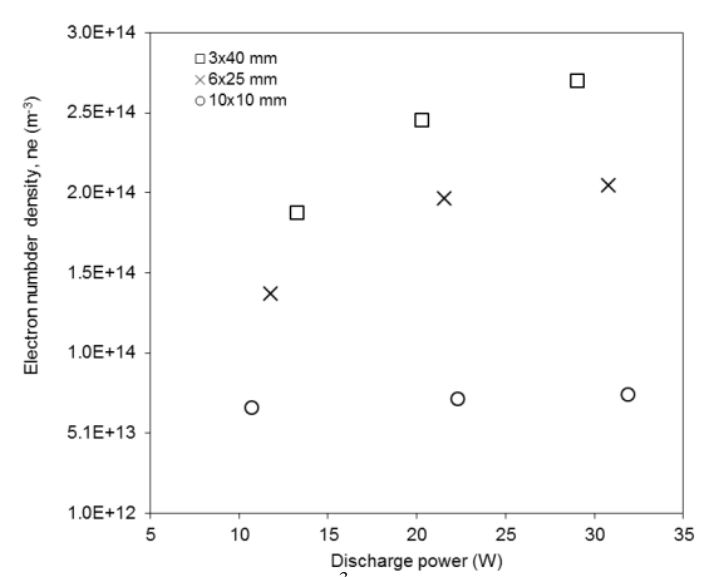

Fig. 6. Electron density, $n_{\mathrm{e}}\left(\mathrm{m}^{-3}\right)$ versus discharge power, $P(\mathrm{~W})$.

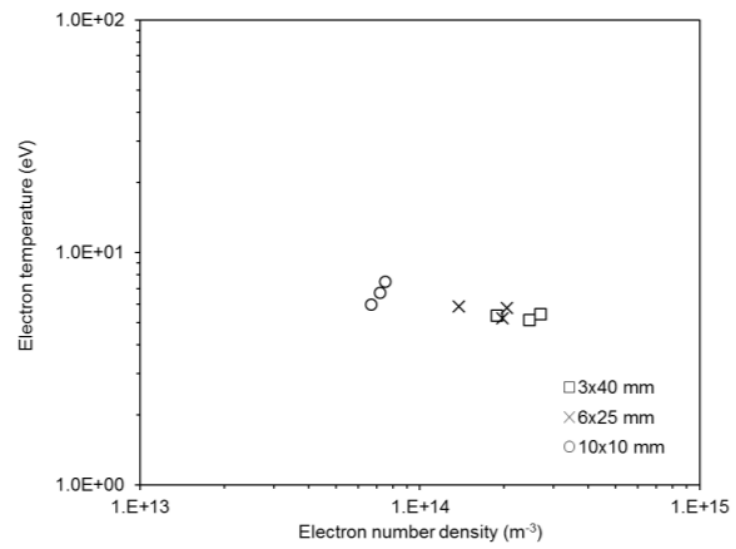

Fig. 7. Variation of electron temperature, $T_{\mathrm{e}}(\mathrm{eV})$ with electron density, $n_{\mathrm{e}}$ $\left(\mathrm{m}^{-3}\right)$.

Fig. 7 shows the variation of $T_{\mathrm{e}}$ with the $n_{\mathrm{e}} . T_{\mathrm{e}}$ decreases with increasing $n_{\mathrm{e}}$; with the three tubes of $40 \mathrm{~mm}$ diameter geometry having the lowest temperature range of 5.1-5.4 eV. This can be attributed to Coulomb collisions between charged particles which becomes more significant as $n_{e}$ increases [1].

\section{B. Ozone Production for Different Geometries}

The pathway of ozone production via electron impact ionization can be described as follows. Upon electron impact, inelastic collisions occur and modifies electronic structure of neutral species, creating excited species or ions [18]. In the case of inelastic collisions of electrons with nitrogen molecules, nitrogen is excited to ions that are in their ground state. When nitrogen ions, electrons and molecules collide, a three body reaction takes place to produce excited nitrogen molecules in the $\mathrm{C}$-state $\left(\mathrm{C}^{3} \Pi_{\mathrm{u}}\right)$, which is at a higher energy level $\left(\mathrm{N}_{2}(v>1)\right)$ [19]-[21]. The excited nitrogen molecule is unstable, and is quenched to lower energy level states $\left(\mathrm{B}^{3} \Pi_{\mathrm{g}}\right.$ and $\mathrm{X}^{2} \Sigma_{\mathrm{g}}$ ) after collisions with the oxygen molecules to generate atomic oxygen via two-step mechanism [20], [21]:

$$
\mathrm{N}_{2}+\mathrm{e} \rightarrow \mathrm{N}_{2}(\mathrm{v}>1)+\mathrm{e}
$$

$$
\mathrm{N}_{2}(\mathrm{v}>1)+\mathrm{O}_{2} \rightarrow \mathrm{N}_{2}+\mathrm{O}+\mathrm{O}
$$

The decay to lower energy states emit an ultraviolet glow, of which spectra is similar to that shown in Fig. 2. In addition to the above reactions, atomic oxygen is produced by direct electron impact dissociation [21]:

$$
\mathrm{O}_{2}+\mathrm{e} \rightarrow \mathrm{O}+\mathrm{O}+\mathrm{e}
$$

Atomic $\mathrm{O}$ recombines with $\mathrm{O}_{2}$ quickly to form ozone $\left(\mathrm{O}_{3}\right)$ based on the following reaction [4], [6], [22].

$$
\mathrm{O}_{2}+\mathrm{O}+\mathrm{M} \rightarrow \mathrm{O}_{3}+\mathrm{M}
$$

where $\mathrm{M}$ is a third body collision partner.

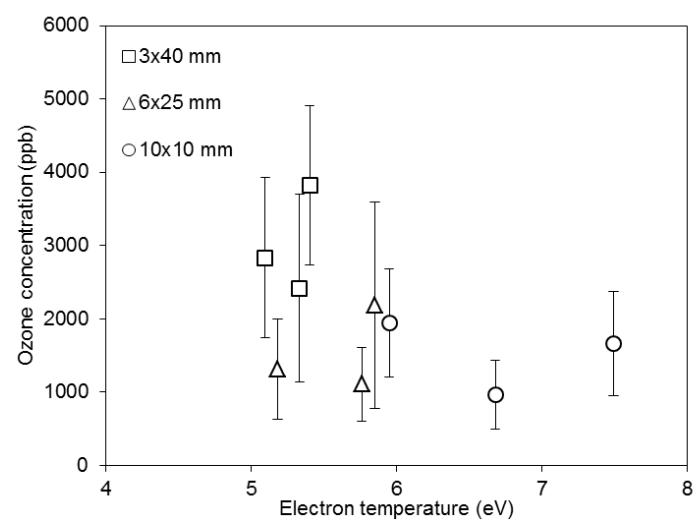

Fig. 8. Variation of ozone concentration with electron temperature, $T_{\mathrm{e}}(\mathrm{eV})$.

As shown in Fig. 8, the amount of ozone from the three tubes of $40 \mathrm{~mm}$ diameter electrode is the highest, showing that the energy via electron collisions has been used (i.e., lower $T_{\mathrm{e}}$ ) to produce ozone. A higher production of charged particles, i.e. higher $n_{\mathrm{e}}$, also indicates that more ozone will be produced (Fig. 9).

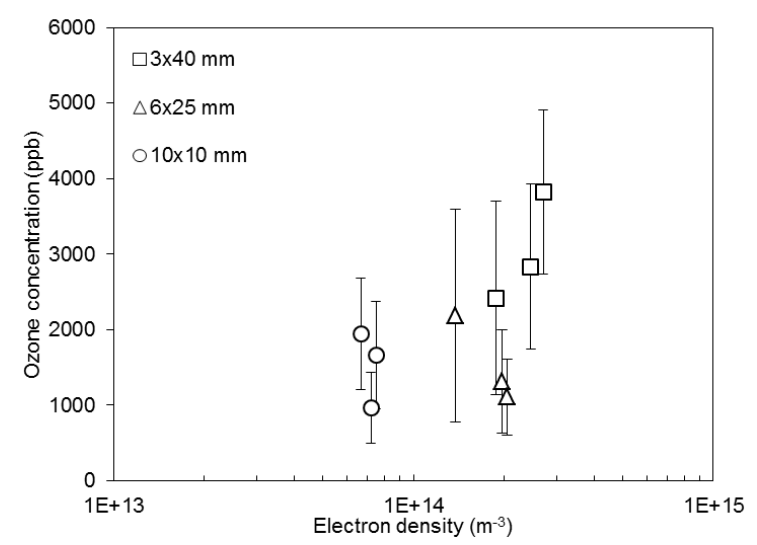

Fig. 9. Variation of ozone concentration with electron density, $n_{\mathrm{e}}\left(\mathrm{m}^{-3}\right)$.

\section{CONCLUSION}

The plasma characteristics of the TNBR NTP discharge has been determined by simulation using a line ratio code developed with MATLAB. Amongst the discharge parameters that were calculated include the reduced electric field, $E / N$, electron density, $n_{\mathrm{e}}$ and electron temperature, $T_{\mathrm{e}}$. The obtained range of $n_{\mathrm{e}}$ were $(0.67-0.75) \times 10^{14} \mathrm{~m}^{-3},(1.4-$ $2.0) \times 10^{14} \mathrm{~m}^{-3}$ and $(1.9-2.7) \times 10^{14} \mathrm{~m}^{-3}$ for the DBD geometries with ten tubes of $10 \mathrm{~mm}$ diameter, six tubes of 25 $\mathrm{mm}$ diameter and three tubes of $40 \mathrm{~mm}$ diameter, respectively. $n_{e}$ is seen to increase with the lower number of tubes due to the 
stronger electric fields generated, which allows for increased ionization and collisional excitation of plasma electrons. $T_{\mathrm{e}}$, on the other hand, is seen to decrease with increasing $n_{\mathrm{e}}$; the three tubes of $40 \mathrm{~mm}$ diameter geometry have the lowest temperature range of 5.1-5.4 eV. This is attributed to Coulomb collisions between charged particles which become more significant as $n_{e}$ increases. The amount of ozone from the three tubes of $40 \mathrm{~mm}$ diameter electrode is the highest, showing that the energy has been used via electron collisions to produce ozone. A higher number of charged particles also indicate that more ozone will be produced.

\section{ACKNOWLEDGMENT}

The authors would like to thank TNB for their funding of this research (TNBR/SF195/2015). The authors would also like to acknowledge the assistance from all of those involved in the project.

\section{REFERENCES}

[1] H. Hao, B. S. Wu, J. Yang, Q. Guo, Y. Yang, and Y. W. Li, "Non-thermal plasma enhanced heavy oil upgrading," Fuel, vol. 149, $162,2015$.

[2] T. Acsente, M. D. Ionita, M. Teodorescu, V. Marascu, and G. Dinescu, "Surface modification of polymethylmethacrylate foils using an atmospheric pressure plasma jet in presence of water vapors," Thin Solid Films, 2015.

[3] M. Fabbri, M. Gigli, M. Costa, M. Govoni, P. Seri, N. Lotti, E. Giordano, A. Munari, R. Gamberini, B. Rimini, G. Neretti, A. Cristofolini, and C. A. Borghi, "The effect of plasma surface modification on the biodegradation rate and biocompatibility of a poly(butylene succinate)-based copolymer," Polymer Degradation and Stability, vol. 121, p. 271, 2015.

[4] M. Babaie, P. Davari, P. Talebizadeh, F. Zare, H. Rahimzadeh, Z. Ristovski, and R. Brown, "Performance evaluation of non-thermal plasma on particulate matter, ozone and $\mathrm{CO}_{2}$ correlation for diesel exhaust emission reduction," Chemical Engineering Journal, vol. 276, p. 240, 2015.

[5] B. Jiang, J. Zheng, S. Qiu, M. Wu, Q. Zhang, Z. Yan, and Q. Xue, "Review on electrical discharge plasma technology for wastewater remediation," Chemical Engineering Journal, vol. 236, p. 348, 2014.

[6] T. Ombrello, S. H. Won, Y. Ju, and S. Williams, "Flame propagation enhancement by plasma excitation of oxygen. Part I: Effects of O3," Combustion and Flame, vol. 157, 1906, 2010.

[7] T. Ombrello, S. H. Won, Y. Ju, and S. Williams, "Flame propagation enhancement by plasma excitation of oxygen. Part II: Effects of $\mathrm{O} 2(\mathrm{a} 1 \Delta \mathrm{g}), "$ Combustion and Flame, vol. 157, 2010.

[8] J. H. Kim, Y. H. Choi, and Y. S. Hwang, "Electron density and temperature measurement method by using emission spectroscopy in atmospheric pressure nonequilibrium nitrogen plasmas," Physics of Plasmas, vol. 13, 2006.

[9] J. Kriegseis, B. Möller, S. Grundmann, and C. Tropea, "Capacitance and power consumption quantification of dielectric barrier discharge (DBD) plasma actuators," Journal of Electrostatics, vol. 69, 2011.

[10] S. Kühn, N. Bibinov, R. Gesche, and P. Awakowicz. "Non-thermal atmospheric pressure HF plasma source: Generation of nitric oxide and ozone for bio-medical applications," Plasma Sources Science and Technology, vol. 19, 2010.

[11] P. Rajasekaran, "Atmospheric-pressure Dielectric barrier discharge (DBD) in air: Plasma characterization for skin therapy," PhD dissertation, Institute for Electrical Engineering and Plasma Technology, Ruhr-Universität Bochum, Bochum, Germany, 2011.
[12] P. Rajasekaran, N. Bibinov, and P. Awakowicz, "Quantitative characterization of a dielectric barrier discharge in air applying non-calibrated spectrometer, current measurement and numerical simulation," Measurement Science and Technology, vol. 23, 2012.

[13] P. Rajasekaran, P. Mertmann, N. Bibinov, D. Wandke, W. Viöl, and P Awakowicz, "DBD plasma source operated in single-filamentary mode for therapeutic use in dermatology," Journal of Physics D: Applied Physics, vol. 42, 2009.

[14] Y. Itikawa, "Cross sections for electron collisions with nitrogen molecules," Journal of Physical and Chemical Reference Data, vol. 35, 2006.

[15] S. V. Pancheshnyi, S. M. Starikovskaia, and A. Y. Starikovskii, "Collisional deactivation of $\mathrm{N} 2(\mathrm{C} 3 \Pi \mathrm{u}, \mathrm{v}=0,1,2,3)$ states by $\mathrm{N} 2, \mathrm{O} 2$, $\mathrm{H} 2$ and $\mathrm{H} 2 \mathrm{O}$ molecules," Chemical Physics, vol. 262, 2000.

[16] K. K. Jayapalan and O. H. Chin, "Effect of neutral gas heating on the wave magnetic fields of a low pressure $13.56 \mathrm{MHz}$ planar coil inductively coupled argon discharge," Physics of Plasmas, vol. 21, 2014.

[17] N. A. Dyatko, I. V. Kochetov, A. P. Napartovich, and A. G. Sukharev, Institute for Innovation and Fusion Research, Troizk, Moscow Region, Russia,1991.

[18] C. Tendero, C. Tixier, P. Tristant, J. Desmaison, and P. Leprince, "Atmospheric pressure plasmas: A review," Spectrochimica Acta Part B: Atomic Spectroscopy, vol. 61, 2006.

[19] B. F. W. Vermeltfoort, "Experimental investigation of plasma assisted combustion using a low swirl burner," MSc. thesis, Department of Mechanical Engineering, Eindhoven University of Technology, Eindhoven, Netherlands., 2010.

[20] A. Starikovskiy and N. Aleksandrov, "Plasma-assisted ignition and combustion," Progress in Energy and Combustion Science, vol. 39, 2013.

[21] H. Hu, Q. Song, Y. Xu, G. Li, and C. Nie, "Non-equilibrium plasma assisted combustion of low heating value fuels," Journal of Thermal Science, vol. 22, 2013.

[22] Y. Ju and W. Sun, "Plasma assisted combustion: Dynamics and chemistry," Progress in Energy and Combustion Science, vol. 48, 2015 .

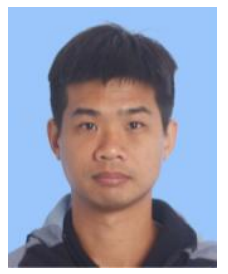

Mooktzeng Lim obtained his Ph.D from University of Canterbury, New Zealand in chemical and process engineering, with focus on hydrodynamics of dual fluidized beds. He obtained his bachelors degree from Universiti Tenaga Nasional in mechanical engineering, while his MSc. studies was with Universiti Sains Malaysia, focusing on a $600 \mathrm{~kW}_{\text {th }}$ bubbling fluidized bed biomass gasifier. He has several postdoctoral stints with University of Canterbury, Uni. Teknologi PETRONAS, and University of Newcastle upon Tyne. Through these experiences, his research has expanded into dual fluidized bed gasification, entrained flow gasification, biodiesel production, and particulate emissions from biomass combustion. Mooktzeng has also worked as a mechanical engineer for three years and was involved in the maintenance department, and is now a Chartered Engineer with the Institutions of Mechanical Engineers (IMechE). He is registered as an Independent mentor with IMechE.

Mooktzeng is currently a principal researcher in the Fuels and Combustion Group of TNB Research Sdn. Bhd. working on non-thermal plasma devices, flame diagnostics, coal and biomass combustion.

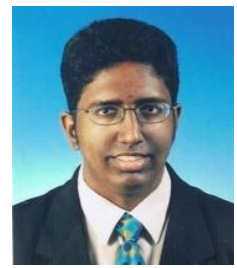

Kanesh Kumar Jayapalan received his B.Sc. in applied physics and the $\mathrm{PhD}$ in plasma physics from the University of Malaya, Malaysia in 2006 and 2015, respectively. He is presently a post doctoral researcher attached with the Plasma Technology Research Center, Physics Dept., Uni. Malaya, working on simulation of atmospheric non-thermal plasma devices. His research interests include inductively coupled plasmas, atmospheric plasma jets and microdischarges. 